\title{
EL FULGOR DE LOS SIGNOS EN LA NARRATIVA DE AUGUSTO CÉSPEDES
}

\author{
Durante un año de la luna, he sido declarado invisible: \\ gritaba y no me respondían, robaba pan y no me decapitaban. \\ JoRGE Luis Borges
}

La historia de Bolivia adquiere una significación de intensidad y totalidad con la Guerra del Chaco; este acontecimiento pudo aglutinar el sinsentido de la sangre derramada desde los inicios de la colonia y procuró explicar la tragedia de que lo increíble sucediera todos los días. Durante estos tres años aciagos, surgió una conciencia revolucionaria entre los cuadros intermedios de combatientes de la "Guerra del agua" y sus ideas impactaron de modo contundente en la vida futura de Bolivia. Entre los pensadores más prolíficos de este grupo se encuentra el cochabambino Augusto Céspedes. Arturo Jauretche dice que Augusto Céspedes "es uno de los intelectuales proscriptos por la inteligentzia". Seguramente a Céspedes se le podría incluir en una lista de escritores andinos destinada a completar el canon latinoamericano ${ }^{1}$ que propusieron pensar el antiguo Alto Perú -y por extensión la América Latina- desde otras perspectivas por medio de una labor intensa desde la literatura, la cátedra, el periodismo y la militancia política y sindical.

'Junto a otros bolivianos como Carlos Montenegro y José Antonio Arze y argentinos como Rodolfo Kusch y Gustavo Cirigliano. Véanse, para el contexto boliviano, EnRIQue Finot, La historia de la literatura boliviana, Gilbert, La Paz, 1964; Fernando Díaz de Medina, Literatura boliviana, Aguilar, Madrid, 1959 y Herbert Kuein, A concise history of Bolivia, Cambridge University Press, Cambridge, 2003, entre otros. 
La obra de Céspedes ${ }^{2}$ representa la desgarradora historia de Bolivia que, en ella, es nombrada, extendida y difundida como tragedia colectiva e interminable. En su escritura se hace deliberada la posibilidad de reencontrar, por medio del lenguaje, una clave que ponga fin a un ciclo de crueldades. La narrativa historiográfica y literaria de Céspedes destruye la distancia del significado porque va más allá de la disolución que otros autores habían intentado. Su contenido se sella con la conjunción extraordinaria de un lenguaje que expresa y transparenta el complejo proceso de reconocimiento de una identidad colapsada. Frente a la "maldición", al "designio fatal", al "destino inescrutable", la obra de Céspedes restituye el intercambio simbólico en la palabra porque decide conjurar los fantasmas que han poblado el nombre de Bolivia y distanciarse de ese placer perverso, recurrente en la historia boliviana, por restablecer continuamente un objeto debilitado.

Los reconocidos relatos de Sangre de mestizos, las biografías noveladas - contaminadas de panfleto y autobiografía-y la novela Metal del diablo, entre sus más destacados escritos literarios, pueden considerarse como integrantes particulares del sistema que constituye la indisoluble obra política y literaria del cochabambino. En su obra se encuentran los relatos más conmovedores de la Guerra del $\mathrm{Chaco}^{3} \mathrm{o}$ la novela señera en la narrativa de las minas, como es el caso de Metal del diablo. Son narraciones atravesadas por el prodigio descriptivo, por la captación profunda de la psicología y la afectividad del valluno desterrado en la selva o en las minas así como por la denuncia de los abusos de poder y la corrupción en todos los estratos de la sociedad boliviana. En concomitancia, ésta es una escritura que ofrece otro tipo de reconocimiento: el de la revelación de una paradoja insostenible, la afirmación de que una operación del lenguaje puede producir y distribuir otros valores y que puede retornar al conocimiento de la realidad mediante artefactos simbólicos. De ahí que la palabra provoque una circulación intensa del deseo en el interior mismo del relato.

${ }^{2}$ He aquí las obras a las que haré referencia: El presidente colgado, Jorge Álvarez, Buenos Aires, 1966; Metal del diablo, Palestra, Buenos Aires, 1960; Sangre de mestizos, Juventud, La Paz, 1969; Trópico enamorado, Universo, La Paz, 1968. En adelante cito por estas ediciones, por título y número de página entre paréntesis.

${ }^{3}$ Dice Joaquín Edwards Bello: "Ninguna obra de réclame comercial o turístico podrá encender tanto amor a Bolivia como las páginas de Céspedes". 
Es una escritura inaugural en el sentido que desborda sus propios límites para explorar un proceso inverso a la expiación y a la destrucción, para, en cierta forma, exorcizar la repetición de un modelo de producción (económica, lingüística, simbólica) que ha deglutido a una nación.

\section{El Chaco}

Sangre de mestizos encarna la comprensión de que lo imaginariamente proyectado se ha disgregado: el ejército, la dirigencia, la conciencia geográfica e histórica, la voluntad política... Revela, desde el título, la adhesión del autor a un programa político y un proyecto social que tomará forma de acción revolucionaria con la creación del Movimiento Nacionalista Revolucionario y con la Revolución de 1952. En ambos casos, el contenido programático de base se fundaba en un sentido xenófobo y reconocía en la raza mestiza su elemento aglutinante. René Zavaleta Mercado explica "la carga ideológica del MNR" destacando el sentido de su nacionalismo:

Pero la lucha de clases, crux del éxito del movimiento, no en el sentido de la posición marxista, "que --lo decía Montenegro-se siente clase en vez de sentirse nación", sino entendiendo la historia de Bolivia como la contradicción antagónica entre la nación, es decir, las clases nacionales, la plebe considerada en su hecho de conjunto, y la oligarquía o la anti-nación o antipatriat.

La "cuestión del Chaco" cumple la función de iniciar una movilización democrática y la formación de conciencia, ya que, en principio la guerra impactó por el mismo hecho de llegar al Chaco -territorio existente, real-donde las situaciones, los roles y los personajes sociales han sido aniquilados; han sufrido un efecto de conflagración. El Chaco se sitúa más allá de un proceso primario de contradicción, de ambivalencia.

Se trata de la muerte, de la ausencia, en definitiva, del sacrificio. Puede decirse que hasta la guerra del Chaco, cada sacrificio en la historia boliviana se dispersaba simbólicamente colocándose en un juego de máscaras y falsificaciones. Sangre

${ }^{4}$ Clases sociales y conocimiento, Los Amigos del Libro, Cochabamba, 1988, p. 87 . 
de mestizos y otras obras referidas a la matanza intervienen en la reabsorción del proceso histórico en fuerza y en potencia; implican un discurso que puede reproducirse según un estatuto diferente. El simulacro del lenguaje devela la ironía de la Historia que, por medio de una nueva generación de sentido, anula el proceso general del capitalismo, es decir, la indiscriminación del individuo como fuerza de trabajo.

Desde el punto de vista de la posesión, el Chaco no fue un territorio realmente poseído, pero sí lo fue imaginariamente. Los vallunos, referidos por Céspedes, arrojados a este monte de densidades climáticas, insectos y enfermedades, creyeron en el alocado pronóstico de la clase dirigente de dejar sentada, en primer término, su existencia, y luego, su presencia en el mapa "de la patria". Sin embargo, un juego malicioso de comprobaciones y de preguntas sin respuesta llevó a la conciencia de que el territorio deseado era simplemente extranjero. Por desconocido y por ajeno. Más aun, la selva chaqueña devela una esencia irónica que sacrifica a los andinos desterrados. Un arco de tensiones configura el recorrido siniestro de un objeto deseado que - en devolución-opone su silencio, se muestra como abismo y, esencialmente, asume su condición de victimario. Los relatos se despliegan desde diferentes núcleos de sentido.

La efectividad del discurso narrativo reside en la repetición formal del dispositivo que apunta a mostrar la inconsistencia de una maquinación falsa y agotada en sí misma. Céspedes renuncia a un formato genérico canónico para fluctuar en una extensión laxa sin pretensión novelesca; una extensión que explora la tensión dramática, las descripciones poderosas y los finales inesperados. La indefinición genérica, nunca inocente, permite descomponer una trama social "abigarrada" en una respuesta definitiva a la histórica manipulación del destino de Bolivia.

En "El pozo", la excursión de la cuadrilla abriendo picadas -soldados eliminados como sujetos, sin disponer de su propio cuerpo ni de su elección- anticipa la condición del monte que los oprime devenido en tumba. Resulta evidente que antes de la orden de cavar el pozo, la tumba está en el territorio chaqueño como partículas de su materia:

$$
\begin{aligned}
& \text { "la calor": "fragua del monte", "fantasma transparente", "fiebre } \\
& \text { cotidiana" } \\
& \text { el aire: "torrente del sol", "beso del horno" }
\end{aligned}
$$


el suelo: "muerte blanca", "duro como cemento"

la sed: "agonía diaria".

La excavación del pozo eclipsa al individuo y hace desaparecer la realidad y sus soportes:

Sigue el trabajo. El pozo va adquiriendo una personalidad pavorosa, substancial, devoradora... Conforme pasa el tiempo, cada vez más les penetra la tierra mientras más la penetran, incorporándose como por el peso de la gravedad al pasivo elemento, denso e inacabable. Avanzan por aquel camino nocturno, por esa caverna vertical, obedeciendo a una lóbrega atracción, a un mandato inexorable que les condena a desligarse de la luz, invirtiendo el sentido de sus existencias de seres humanos... (Sangre de mestizos, "El pozo").

La tensión descendente aparece distorsionando cada categoría benéfica. La cuadrilla conoce su trabajo y el precario campamento se ofrece como guarida; empezar a cavar el pozo invierte el sentido de conocer en desconocer porque cada personaje se contamina de la inseguridad de buscar agna. El pozo, en tanto objeto fantaseado, augura frescura en los pies descalzos de los andinos y cada día de trabajo parece dejarse poseer. Sin embargo, el paso del tiempo que - en su condición de fantaseado es, en consecuencia, desfigurado, trasmutado- es a la vez "tiempo lijo" y "sueño de caída infinita", se materializa en el terror de perder la orientación, el sentido y los mismos cuerpos ya cubiertos de polvo. Complementariamente, gravita la mortuoria anticipación "del polvo que vuelve al polvo":

Cada vez que los veo me dan la sensación de no estar formados por células, sino por moléculas de polvo, con tierra en las orejas, en los párpados, en las cejas, en las aletas de la nariz, con los cabellos blancos, con tierra en los ojos, con el alma llena de tierra del Chaco (Sangre de mestizos).

La batalla final regresa al ideal de poder disponer de la vida, de vencer, de vivir. La trama se invierte en objeto vacío, inaccesible y por tanto inútil y peligrosa: morir en la guerra del Chaco. El pozo, objeto ambivalente, que habría dado agua entendida como salvación, como vehículo, como mutación, queda fijado en la inmutabilidad simbólica de la tumba de los muertos en combate. 
En esta situación de orfandad, la guerra se convierte en vacío, en una marcha sin apuestas que permanece entregada a una dramatización artificial. La cualidad de fatal de este suceso podría leerse, en Céspedes, como una escalada a los extremos en un movimiento dual e indefectiblemente destructivo, es decir, la autenticidad de la lucha se pierde en una tensión luctuosa donde el segundo término aniquila cualquier bienestar imaginado: conocer/desconocer, tener/perder, vivir/morir. De manera que los relatos potencian el choque, la extrañeza y la irrealidad en un núcleo de sentido que pone en evidencia la dispersión del objeto deseado.

Aparentemente, cada episodio en Sangre de mestizos toma "parcelas" de la realidad por medio de anécdotas diferentes, es allí donde los núcleos de sentido hacen que el lenguaje se convierta en acontecimiento puro. La fotografía encontrada, el amor perdido, la naranja apetecida por el agonizante, las ratas de cada noche o el pozo funcionan como equivalentes virtuales de un territorio nulo y desaparecido: en definitiva, la tragedia de la guerra.

\section{LAS MINAS}

La revisión de la cuestión del Chaco forma parte de lo que podría llamarse el aparato mítico de las movilizaciones que desembocaron en la revolución de 1952. El MNR -cuyos ideólogos de base fueron Augusto Céspedes y Carlos Montenegro- se integra, luego de la matanza de Catavi, ocurrida en 1941, "a los movimientos reivindicacionistas en las minas que hasta esta fecha habían terminado en el aislamiento y la represión localizada, sin verdadera repercusión en la política nacional como tal"5. Catavi precipita la caída del presidente Peñaranda y el gobierno de Villarroel adquiere el sentido de un pacto entre los movimientos mineros y la dirigencia pequeño burguesa de grupos como el MNR.

Estos hechos toman vigor en el discurso de Céspedes cuya obra no puede reducirse a un reflejo de la realidad de su país ni a una denuncia. Todo lo contrario, su ideología desborda la escritura como desbordó los acontecimientos que se desencadenaron luego de la guerra del Chaco. Se trata de una obra crí-

${ }^{5}$ Cf. R. Zavaleta Mercado, op. cit., p. 23. 
tica, incluso, del dominio propio de su ideología y de su militancia. De ahí que leer sus libros como aislados le restaría plenitud y convocatoria; la literatura de Céspedes es un proceso, un continuum, que anula la diferenciación superficial de géneros, asuntos y hechos históricos. La interpretación crítica y la propuesta estética se disuelven en una instancia alegórica que traspone pensamiento, palabra y acontecimiento.

En este sentido, la novela Metal del diablo, forjada más allá de la representación de la realidad, produce un vuelco alegórico que supera la degradación de la vida en las minas bolivianas, a su fantasma negativo y a su carga de estigmas. Materializa una energía latente para volverse el signo descifrable de la crítica a la oligarquía de los empresarios mineros y terratenientes. Una operación basada en principios de simbolización dispersa al Chaco en una diferenciación de singularidades - el pozo, las alimañas, la sed, el valor militar, el hospital de veteranos-y en un procedimiento de reabsorción, el Chaco se revierte en la instancia de nación atravesado por la clausura de un lenguaje que dice lo no dicho:

Ahora eres patria, Chaco,

de los muertos sumidos en tu vientre

en busca del alma que no existe en el fondo de los pozos...

(Sangre de mestizos).

Con lógica idéntica, la creación del personaje de Zenón Omonte articula la historia inverosímil de Simón Patiño con la increíble historia de Bolivia. Aparentemente, Céspedes habría optado por repetir la historia del legendario minero. No obstante, como artista no muestra la realidad sino, como dice Jean Lyotard", lo que muestra es "el juego de sus figuras en el orden de la percepción y del lenguaje". Al convertirse Patiño en Omonte, se expone su fantasma como realización del deseo y como procedimiento estético. Allí se consolida el símbolo. A propósito, Borges escribe: "Omitir siempre una palabra, recurrir a metáforas ineptas y a perífrasis evidentes, es quizá el modo más enfático de indicarla" su carácter puramente novelesco porque apunta a totalizar el sentido a la vez que hace ambiguo el referente. Escribir la vida

${ }^{6}$ Derive a partir de Marx et Freud, Union Générale d'Éditions, Paris, 1973.

7 Jorge Luis Borges, Ficciones, Alianza, Madrid, 1998. 
de Patiño en un formato novelesco significa crear una cosmogonía, un universo con leyes propias que al mismo tiempo se determina en una reversibilidad con la realidad al configurarse en símbolo. Su principio de funcionamiento tiene que ver con crear un universo verosímil que toma permanentemente datos verificables tales como informaciones de periódicos, cifras y nombres reales para, inmediatamente, negarlos en una proliferación figurativa que queda fijada en el interior del ciclo simbólico.

La novela comienza con unas notas bajo el título de "Avisos económicos" que parecen asegurar el inicio del relato de una historia "verdadera" y, por ello, documentada, "certificada" en archivos y periódicos. La lista de avisos se cierra con la ironía - también contenida en el título de la novela- de desmentir la verdad de los acontecimientos que se narrarán. Un procedimiento estético, como en este caso es la ironía, volatiliza el espectro de los datos "verdaderos" y los moviliza hacia una fuerza ambivalente capaz de conceder reversibilidad y potenciar el intercambio.

En sentido envolvente, el mismo procedimiento de inversión opera metonímicamente entre la reproducción de la noticia "aparecida en periódicos de Nueva York" y el capítulo 2, "Clima del valle". Opuestos discursiva y tipográficamente, presentados el uno como infracción del otro, ambos capítulos conforman el plan de la novela, es decir, exhibir la disolución de la repetición - de lo fantasmal- para apresar la escandalosa historia de la minería boliviana en la circulación del orden simbólico. El anclaje simbólico se establece en leyes sutiles que se sustentan en la ambigüedad y la polisemia dispuestas en una sucesión de referentes distorsionados. Entonces, a la transcripción de la noticia periodística sucede la narración de "la mula de oro" que Zenón encontró. El episodio de la mula de oro y la mula de oro por sí misma inician una sucesión alegórica de eslabones que se implican y se contienen unos en otros en la superficie discursiva:

Comprobada la practicabilidad del vado, se introdujo a la mula que llevaba el cajón de madera conteniendo oro, y fue fatalmente ésta la que tropezó, resbaló y cayó. Envuelta por las aguas, fue arrastrada un corto espacio en su turbio desorden de piedras y remolinos. Los arrieros agarrándose como sapos de los pedro- 
nes, vieron que la carga se desprendió de los lomos del animal y desapareció en el torrente...

La mula descargada logró salir por sí misma, llena de barro, hacia la orilla. Entonces fue necesario que bajase la creciente para buscar el cajón... (Metal del diablo, p. 20).

Entre los muchachos que buscaron el cajón, Zenón fue quien lo halló. El episodio funciona como el enunciado de lo posible y de lo imposible: de quién es Zenón, de quién será. La primera frase "La mula de oro cayó al río..." indica, en su ambigüedad, que el lugar deseado es Cochabamba, sus valles, su río: la infancia. En segundo, anuncia que este espacio será un recuerdo para Zenón, que él estará en otro lugar, en otro pensamiento y en otro destino. Y, finalmente, la mula de oro aglutina uno de los sentidos fundantes de la novela, es decir, el suceso excepcional de que un cholo de Karasa encuentre un tesoro, el suceso excepcional de que lo imposible sea posible. La potencia de esta imagen reside, de suyo, en que el encuentro del tesoro implica la pérdida del paraíso.

La mula, además de ser una metáfora del destino de Zenón y en extensión de la nación, funciona como la absorción de la multiplicidad de imágenes que conforman narrativamente el itinerario vital del cholo de Karasa. La mula de oro se traslada a otros espacios, es la llave que hace posible el hallazgo de la veta de estaño más grande del mundo.

Diez años después, cuando Zenón está en Oruro, encuentra casualmente a don Rigo, el dueño de la mula que, en nostálgico agradecimiento, lo recomienda en la casa Bottger, donde el cholo aprenderá a "apreciar" metales. Este episodio está enmarcado por un sueño de borracbera:

Retornó a su cuarto y se acostó. Antes de sumergirse en un sopor, sintió resonar en su cerebro palabra nuevas e inauditas... Alanta$\tilde{n} a$, barrilla, ingenio, Uyuni, piña de plata, y vio las caras de Francisco I y de don Rigo, llenas de confetti que se esparcían entre los cristales rotos en el fondo del sueño (Metal del diablo, p. 46).

Es un sueño premonitorio, anclado en la tradición popular, ambiguo en su significación, principio de peripecia y que deja adivinar la contradicción de fortuna y desgracia implícita en la historia. La trayectoria dialéctica de Zenón está marcada por el deseo profundo de cambiar su destino y aparece movilizada por la metáfora de la mula de oro que aflora, después del en- 
cuentro con don Rigo, en los personajes que encadenarán el ciclo simbólico como el reverso del propio Zenón. Estos personajes son Nepomuceno Ramos, el indio Huachipondo y su compañero Cisco. Todos estos están conectados directamente con el sueño premonitorio y pertenecen, en tanto sujetos del saber, al orden de la predestinación. El destino como forma recurrente se representa, en consecuencia, como duplicación. Los indios eran conocedores de minas y vetas desde el tiempo de los españoles, "Huachipondo... partía las rocas superficiales, para llevar hasta los poblados pedazos de piedras relucientes que maravillaban a los blancos" (Metal del diablo). A continuación, este pasaje de la novela se cierra con un listado de fechas y el recuento de bocaminas agregados como datos fidedignos en una nota al pie. El relato se vale, otra vez, de procedimientos que involucran la reversibilidad y potencian la verosimilitud, como modo de rehabilitar lo fantasmal.

El pasaje inmediato comienza diciendo: "Más relucían, empero, las historias del comerciante español José Centeno". Los ecos del "cristal roto" ofrecen su máximo de intensidad. Corre esquiva y fantasmal entre los parroquianos la historia de Huanchaca que José Centeno procede a aclarar, a hacer "relucir": es la historia de Argadoña, un cholo que, con el secreto de un indio, encuentra una mina de plata. Zenón puede oír el final de la conversación con el suspiro: “-iQuién fuera Argadoña!". De este modo, todos los signos de brillar, relucir, resplandecer, se explican recíprocamente; los encadenamientos tienen sentido y tienen relaciones.

Los indios, Nepomuceno, Centeno, los que saben, son los gestos del tiempo que desaparecerá y del que se realizará. Nepomuceno es quien "aprecia" metales, los toca, los sopesa, los observa; Huachipondo dice que sus llamas se convirtieron en llamas de plata, Cisco es quien ve la veta por primera vez:

Sin hablar, Omonte coge algunos fragmentos y los saca a la luz del día. Negros y brillantes destellan al sol. Nervioso saca más pedruzcos... todos, todos eran pedazos de roca, de colores furtivos y sombríos, con fulgores astrales, pesan cada vez más, irradian, queman como meteoros, transmiten a las manos de Zenón Omonte una certidumbre portentosa como el alumbramiento: el indio Cisco Tajuara ha cortado la veta de estaño más rica del mundo (Metal del diablo, p. 88). 
El encadenamiento de signos contenidos en Nepomuceno y Huachipondo, al trasladarse a Zenón, establece un contrato de intercambio, no de alianzas sino de apariencias. La mina tiene un muerto y Huachipondo lo sabe. Allí, la fortuna se reviste de forma extraña e inaceptable, se revierte en desgracia. Zenón transita de la premonición al "alumbramiento" y la posesión del "metal caído de un estrella", en tanto duplicidad de los sujetos del saber, en sujeto del poder. El poder no puede ser ejercido como facultad unidireccional de decidir sobre la vida de los demás ${ }^{8}$, por el contrario, se juega en la ambigüedad que hace girar, a quien lo ejerce, alrededor de un siniestro privilegio. De esta ironía se desprenden los males que sostienen la existencia del rey del estaño. La mina "que tiene un muerto adentro" es la contrapartida de la mula de oro y las llamas de plata. En una operación de equivalencia, la desgracia, igual que la fortuna, queda fijada en signos de cristal roto, de brillo y de fulgor. La ironía se condensa en el título de la novela: el metal caído de una estrella es al mismo tiempo el metal del diablo.

Con valor opuesto, la desdicha se significa encadenada y potenciada en sacrificios y masacre. Se acumula rápidamente - como la fortuna del rey del estaño-y sus signos circulan inversos a la fortuna: del subsuelo boliviano, al suelo, a Zenón; de Zenón, al suelo, al subsuelo. La primera aproximación de los males a Zenón son las pecas de Antonia; cual chispas, la compradora del rifle las lleva como la revelación del estigma de la expulsión del paraíso - Cochabamba-y del muerto dentro de la mina. Las lleva, además, como consecuencia de la fatalidad que sacrifica el encanto del brillo del metal a la vez que lo produce. El rifle que trae Antonia viene acompañado de un presentimiento amargo: “¿Qué tendrá el (hijo) menor que no quiere mamar y llora de continuo?".

La explicación del título de la novela ocupa las primeras líneas de "Avisos económicos" y da paso a la paradoja que contamina la totalidad del universo novelesco. Siendo en sí mismo un enunciado paradôjico - por cuanto lo infernal se asocia a la oscuridad y lo metálico a la luminosidad - la eficacia simbólica se logra por el efecto de sentido de que el "precio" de lo brillante se mide con una medida mortuoria y por la estrategia

8 Cf. JEan Baudrillard, Las estrategias fatales, Anagrama, Barcelona, 1984, p. 77: "el poder, igual que la verdad es ese lugar vacío que hay que saber no ocupar nunca, pero que hay que saber producir". 
narrativa característica que, para este caso, elige Céspedes, es decir, volver ambiguo el referente verificable acreditando fuentes autorizadas como el National Geographic Magazine.

En el universo novelesco, la enfermedad del hijo, figurada en gritos, dentelladas y desmayos fulminantes, lleva consigo la discriminación y con ella la mortificación. El tema de la enfermedad implica el encadenamiento de desdichas - sobreentendida en un sistema propio de signos- y lleva en sí la contaminación, es decir, "el enfermo es también mortífero y se venga como puede". El hijo, convertido en peligroso, al comienzo negado, después apartado, finalmente encerrado, dará a la vida de los Omome todo su potencial de maleficio.

Tales maleficios se organizan encadenados $y$, en preponderancia, tienden a abarcar lo social; los "fulgores astrales" se derraman sin debilidad sobre Zenón, en quien toma sentido el intercambio de acuerdo con un sistema de profundidad causal. En el ámbito público, la figura de Zenón se activará por medio de los pleitos, instalados narrativamente desde la compra del rifle y alegóricamente desde la sociedad con Nepomuceno y la transacción con Huachipondo. La otra cara de los cristales rotos actúa como maldición en las demandas y en la puesta en ijuego de la condición de avaro del protagonista; el pleito es el aglutinante de las relaciones sociales que establece. Los signos del resplandor se especifican en colores que van de lo áureo y plateado (la mula de oro, las llamas de plata, el meteoro) al rojo del llanto del niño enfermo y de la rabia del rey del estaño en un encadenamiento fatal. La iluminación opera su tendencia infernal (los accidentes con dinamita, las ráfagas de rifle, la sangre regada en la plaza) y va del cielo al subsuelo y de la opulencia al sacrificio:

Golpeando la mesa de su escritorio, la indignación lo sofocaba, incendiándole con el riego congestivo que le inundaba los pómulos de rojas redecillas venosas:

- ¡No señor! ¡Yo no me hago robar! Han creído que porque soy Omonte debo... debo... (Metal del diablo, p. 208).

La mina es la forma consumada del mal porque se sitúa en el límite de la exterminación y del suplicio sin fin. Los mineros son condenados a nacer y a morir en el averno subterráneo. El valor de sus vidas se codifica en el desvío y la opacidad del valor sígnico. El enjambre humano, que arranca de las entrañas de 
la tierra al vengativo metal, responde al más avanzado proceso de manipulación de la relación social: reducidos a significar según la ficha que dejaron a la entrada de la bocamina, determinados al silencio y al ensordecimiento del centro del planeta. El control, para el caso de la minería boliviana, responde a una mutación que corroe la condición humana a través del trabajo forzado, el aire contaminado y la negativa a los derechos civiles. La inscripción del dolor se formaliza en la descripción de la vida en las minas. Su sentido metafórico se absorbe por el pacto Zenón/diosa inorgánica. La mina, en su ritual de muerte, representa las tinieblas a las que Zenón es arrojado cuando huye de Cochabamba. El paso descomunal entre la fortuna y la desdicha, entre la riqueza y la miseria es, en definitiva, el intercambio simbólico de las diferencias entre lo astral y lo infernal: del "metal caído de una estrella" al "metal del diablo". Intuición del mal y de la muerte, lugar de la degradación y el encierro, la mina se codifica míticamente en signos de lo infernal donde "la dantesca oscuridad", el fuego, el sulfuro y el polvo dejan fijado el sentido del agujero y del horno como tumba.

La organización de la mina es un espacio neutralizado a la vez que lugar de la indiferencia y la reproducción del sistema económico que la genera. Es también, como en el caso de las ciudades, una reproducción hacia la profundidad de la destrucción simbólica de las relaciones humanas. En esta "urbanidad", la muerte hace jugar entre sí a todos los signos bajo la alternancia fácil de lo sano por lo enfermo, de los cuerpos por el metal "apreciado" y de la indiscriminación noche/día como modo de anular la temporalidad porque todo siempre es oscuro en esta cara del "cristal roto" (lugar donde puede intercambiarse otro momento, el de nacimiento/muerte, sin ser uno término del otro sino una noche indeterminada por el abuso). En el campamento minero, la muerte se readapta en el mal de mina, los accidentes y la alimentación deficiente. Se anuncia en estos signos, se perfecciona metafóricamente en complicidad entre la diosa metálica y la avaricia de Zenón, y se fija simbólicamente en la función de la manipulación económica y del control social.

Un cuerpo, conminado a ser violentado, neutralizado o silenciado, rechazado o mortificado, reducido a la utilidad pesada en especies en la pulpería de Omonte, podrá instalar en el vacío el momento de una contigüidad histórica que disuelva la simulación del cuerpo y que lo restablezca en su naturaleza me- 
diante la protesta y la huelga. Pero no se trata de un proceso de liberación instantáneo; si la protesta se generaliza, el veto sobre el cuerpo se perfecciona en el soporte de la represión. En este caso, lo que sí se generaliza es la referencia que Metal del diablo pretende potenciar basándose en procedimientos estéticos reveladores de la paradoja y la ironía; con ellos pone en evidencia el reverso simbólico de la acumulación de riquezas y su precio: la matanza de Catavi.

Céspedes dedica el capítulo "Filón de sangre" para mostrar en detalle los entretelones de la huelga, la llegada del ejército y la represión final. Esta previsible sucesión de la anécdota se despoja de su forma concreta para actuar desde el fulgor transmutado en el rojo y el colorido desorden de ponchos y sombreritos redondos en que se ha convertido la multitud. Es en la confusión y en el presentimiento de la sangre donde la muerte se instala como principio fundante. Igual que la figura de Zenón, este momento crucial es opacado con signos de "desmentida" - en sentido freudiano-y de fulgor:

Una alegría rojiza iluminó los rostros de los altos empleados.

-Ahora que griten. jA hora los va a hacer humear a estos bandidos!...

Los tumultos crecían en forma de rumor, irradiando un pavoroso malestar de pobreza enfurecida. Los fusiles de nueva fracción de soldados aparecieron delante de los obreros... el pueblo quedó en una inmovilidad atónita que sólo rayaron unos disparos aislados de fusil. Puertas cerradas. Todo quieto: las casuchas, los cuerpos caídos en ademán de fuga, mostrando las canillas. Sólo la sangre corría lentamente entre el polvo y las piedrecitas del pavimento, debajo de las caídas figuras, como una roja sombra infrahumana (Metal del diablo, p. 204).

La falsificación de datos y del saldo de muertos por parte de Omonte (ningún soldado murió en la represión) podría demostrar que la producción de muerte es susceptible de falsificación. Sin embargo, el principio de realidad no permite escapatoria, puede revelarse en el sistema alegórico que subvierte el referente en signos que lo revelen. La cantidad de muertos situada en la nebulosa de la discusión de si fueron veintiocho o cientos se sustituye por la modalidad de un universo figurado en risas congestivas, ráfagas de ametralladora, sangre corriendo entre los adoquines de la plaza y gritos en quechua que buscan un marido desaparecido. Siendo el hallaz- 
go de la veta el primer centro tensivo de la novela, la matanza de Catavi funciona como su doble y su contracara. Ambos se condicionan para evidenciar la impostura histórica del episodio de la minería boliviana hacia un sistema alegórico que juega su "propia verdad" en el intercambio de riquezas por sangre y de metal por diablo.

Probablemente, todos los relatos históricos se configuren como simulación y su manera de existir sea la falsificación. Cuando el valor de preeminencia de una literatura como la de Céspedes reside en su potencia definitoria es cuando puede actuar simultáneamente sobre todas las instancias (lenguaje, referente, ideología, acción revolucionaria). Es allí donde puede llevar una especie de existencia segunda con respecto a la Historia y convertirse en su fantasma, su conocimiento y su sentido.

Estamos frente a una obra cuya cualidad es doblemente revolucionaria. Desde lo literario, porque potencia la originalidad y la capacidad de ilusión para hacer resplandecer una forma de lenguaje convertido en objeto puramente estético. Y desde lo social, porque consigue imponer la convicción de que para mostrar un mundo entero y un acontecimiento totalizador sólo es necesario determinar cualquiera de sus detalles y prefigurar su camino inexorable. 
